\title{
Educação e Treinamento a Distância Mediados por Computador: em busca da Aprendizagem Significativa
}

\author{
Gisele Costa ${ }^{1}$, Lisandra Nascimento ${ }^{1}$ \\ ${ }^{1}$ Formandas em Pedagogia Multimeios e Informática Educativa da Faculdade de Educação - Pontifícia \\ Universidade Católica do Rio Grande do Sul (PUCRS) \\ Av. Ipiranga, 6681, Prédio 15, sala 219 - Porto Alegre - RS - Brazil
}

\{giselemcosta, lisandralves@terra.com.br)

\begin{abstract}
Resumo. Este artigo visa identificar o desenvolvimento da Educação a Distância (EAD) mediada por computador em âmbito empresarial e educacional no país. Busca enfatizar a utilização dos recursos tecnológicos e identificar os pressupostos básicos na educação a distância proporcionando a esta uma aprendizagem mais significativa. Reflete sobre a tomada de consciência de diversas empresas nesta área e as necessidades de disseminação da mesma.
\end{abstract}

\section{Contextualização da Educação e do Treinamento a Distância no Brasil}

A educação a distância surge no Brasil como uma forma de "salvação" à educação básica. Inicialmente por correspondência, depois rádio, televisão, chegando ao que hoje conhecemos: o computador. Nesta abordagem, promovida principalmente pela Internet, pode- se oferecer níveis comunicacionais avançados: chats, fóruns, e-mails ou permanecer com a forma de ensino tradicional, ou seja, o professor-tutor detém o conhecimento e este é repassado aos educandos.

No contexto empresarial, a educação a distância aparece como uma maneira de treinamento visando suprir a necessidade de mão-de-obra qualificada do país. O que não impede de esbarrar em problemas como o analfabetismo, a falta de conhecimentos informáticos e a ausência de programas e professores especializados nesta modalidade de educação. Entretanto, a educação a distância cresce consideravelmente em nossa sociedade, acarretando uma busca constante por novas formas de aprendizagem e profissionais adequados a esta nova realidade.

Assim, o ensino à distância vem ao encontro de respostas às necessidades de uma sociedade caracterizada pela competitividade, em que a questão do "tempo" é um fator crítico no desenvolvimento dos indivíduos e das instituições. MARTINS (1998), nos traz referências quanto ao nosso olhar frente ao novo tempo, chamado de tempo das redes, e espaço, em que a cibercultura e a telepresença imperam, destinadas a unir pessoas que estão impossibilitadas geograficamente.

COSTA (2002), coloca a educação a distância como forma de apresentar uma alternativa para a sociedade que exige a disponibilidade do conhecimento a qualquer momento, em qualquer lugar e, sobretudo, quando necessário e oportuno. 


\section{Recursos Tecnológicos e Pressupostos Básicos á Aprendizagem Significativa}

A educação a distância mediada por computador deve apresentar recursos tecnológicos variados para centrar-se como uma prática significativa ao processo ensino-aprendizagem. Para tanto, reconhecemos a importância de alguns destes meios e enfatizamos seus usos aliando aspectos técnicos aos pedagógicos para possibilitar o aprender contextualizado.

O auxilio das tecnologias à educação está na construção da curiosidade, da imaginação, da autonomia, enfim, do conhecimento, distante do ambiente quase monótono, monofônico e monocromático das salas de aula tradicionais.

Hoje, muitos dos cursos disponíveis a distância atentam para a quantidade de recursos e não preocupam-se com seus usos, o que ocasiona uma supremacia do técnico sobre o pedagógico, acarretando o desinteresse pela mensagem e a aprendizagem focada em perfis tecnológicos. Ou seja, quando almejamos capacitação, é necessário adequarmos o treinamento aos conhecimentos prévios do treinando, sejam estes técnicos ou pedagógicos e quando nosso objetivo é a educação formal, a tecnologia deverá estar intrínseca ao processo.

Desta forma, caracterizamos alguns recursos tecnológicos como pressupostos básicos para o fazer pedagógico significativo, sendo eles: comunicacionais, de interação, de avaliação, de mediação e de colaboração. E também algumas mudanças paradigmáticas como: autonomia, confiança, criatividade e criticidade.

Assim, a modalidade a distância exige que os materiais de instrução sejam muito bem planejados e elaborados entre os sujeitos ativos da aprendizagem, pois está mais presente a necessidade desta interação pedagógica entre alunos e professores, caso contrário há possibilidade de fracasso em sua utilização. 


\section{Recursos de Comunicação}

A educação a distância deverá ser tomada como uma nova forma de educar e não mais como uma "roupagem" para a educação tradicional, apresentando técnicas inovadoras como autonomia crítica e processos mediados pela comunicação síncrona e assíncrona, a última pouco utilizada na formação presencial.

A reformulação das formas vigentes de aprendizagem faz-se cada vez mais necessária. Precisamos introduzir os meios comunicacionais existentes nesta prática. Enriquecendo criativamente o processo de educação continuada, permitindo maior flexibilidade, interatividade e participação dos usuários.

Com estas mudanças, é mais perceptível a necessidade de nos comunicarmos através de outros meios. A comunicação está mais sensorial, multidimensional e menos linear. Para MORAN (1995) a multimídia apresenta uma mudança significativa neste momento, pois através dela podemos dispor de sons, imagens e textos para nossa comunicação.

Atualmente não podemos utilizar somente um tipo de comunicação, apesar de estarmos na era do telefone celular, dos chats, das conferências eletrônicas, a comunicação assíncrona continua sendo de extrema importância, seja ela através de publicações impressas, mensagens eletrônicas ou qualquer outro meio.

Desta forma, visualizamos a educação com as múltiplas capacidades de desenvolvimento que os meios comunicacionais nos proporcionam, realizando mais constantemente o diálogo do que possivelmente em aulas presenciais. Pois neste modelo, se as aulas não apresentam-se como forma de intervenção tornam-se desinteressantes e amputam o desenvolvimento da criatividade e da cooperação. 


\section{Mediação e Autonomia}

De acordo com MATURANA (1998), a autonomia produz seus componentes através da interação com o meio, é um estado de autoconsciência.

Desta forma, a EAD deverá apresentar como foco a crítica, tornando o aluno o sujeito de sua aprendizagem, este que aprenderá de forma autônoma. BELLONI (2001), ao falar sobre educação a distância afirma que a aprendizagem será vista como um processo permanente, em que os educandos deverão ser autônomos na busca de conhecimento e o papel do professor será o de mediar esta busca.

Os resultados da educação a distância possibilitam conhecer novas técnicas de apresentação de conteúdos e também promover a aprendizagem tecnológica dos meios a serem utilizados pelos alunos para esta prática. Quando os alunos estão utilizando redes de comunicação, é importante que o professor possua manejo para auxiliar o aluno a perceber as mensagens encobertas, ou seja, a necessidade que hoje existe é tornar o aluno ou mesmo o profissional, mais crítico a respeito do que leu, viu ou ouviu por aí.

Assim, a autonomia é "ferramenta" essencial quando se fala em educação a distância, pois não verifica-se a presença física do docente, ficando a cargo do próprio aluno a organização de sua rotina de estudos. 


\section{Interação e Criatividade}

As novas formas de interação tecnológica estão modificando nossos valores. NEGROPONTE (1995), crê que a idéia de nação cada vez mais cede espaço a de comunidades virtuais, em que o espaço é irrelevante e o tempo assume um outro papel, possibilitando demonstrarmos nossa diversidade cultural.

Neste contexto, a EAD necessita de formas de interação que abram espaço ao diferencial, a liberdade de expressão, a criatividade. Pois, de acordo com KNELLER (1988), a criatividade estimula, enriquece, contribui para o processo educativo, devendo o professor auxiliar os alunos a examinar as novas idéias e não descartá-las sem reflexão.

Tudo isso possibilita uma série de novas experiências e interações que bem trabalhadas enriqueceriam a educação. Porém, para que o professor possa propor boas situações de aprendizagem utilizando a Internet, é fundamental problematizar os conteúdos, definir objetivos e assumir-se como facilitador de seus alunos na busca de soluções, no gosto pela pesquisa, ao levantar questionamentos e, principalmente, em relação a posição crítica a tomar frente as informações disponíveis na rede, pois quantidade não representa necessariamente qualidade.

Portanto, é imprescindível que a educação formal adeqüe-se a esta nova realidade e que os professores ensinem seus alunos a aprender a aprender juntamente com o aprender a pensar criticamente, utilizando-se dos variados meios de comunicação e das novas tecnologias, proporcionando uma visão global emancipatória e um maior nível de raciocínio aos mesmos. 


\section{Colaboração e Criticidade}

"O ciberespaço, dispositivo de comunicação interativo e comunitário, apresenta-se justamente como um dos instrumentos privilegiados da inteligência coletiva. É assim, por exemplo, que os organismos de formação profissional ou de ensino a distância desenvolvem sistemas de aprendizagem cooperativa de rede". (LEVY, 2001, P.27)

O espaço virtual não deve ser comparado ao presencial; deverá apresentar-se mais colaborativo, pois só é possível ao professor-mediador acompanhar o desenvolvimento cognitivo de seu aluno se este utilizar-se das ferramentas disponíveis para seu aprendizado, sendo estas inerentes ao curso ou não.

Para tanto, os professores têm de ser capazes de pensar junto aos alunos, de formar para a cidadania e para a democracia. No contexto tecnológico atual, se faz necessário que os profissionais se informem e saibam se comunicar (domínio cultural de diversas áreas). E para que isso ocorra a educação tem de preparar esse indivíduo.

Através das percepções de seus alunos o professor tem o dever de inseri-los em uma cultura da crítica em que existe manipulação e profissionais incapazes de analisar as ideologias que utilizam, não em um mundo de ingenuidade e dos sonhos fabricados pelas imagens. Também, COGO (2001), trabalha nesta perspectiva, ao perceber nos usos das tecnologias informacionais a relevância educacional provocada pelas leituras e interpretações das mesmas.

Assim, GUTIERREZ e PRIETO (1994), vêem nos processos de interaprendizagem a forma de trabalho grupal capaz de enriquecer o processo de açãoreflexão através do confronto entre idéias e opiniões. O que nos leva a redimensionar a abordagem a distância, pois o trabalho colaborativo deverá ser priorizado, não compulsório, colaborando para que o uso das ferramentas de comunicação e informação seja feito sem cobranças, partindo da interação e colaboração do educando com o meio. 


\section{Avaliação e Confiança}

Em educação a distância um ponto importante a ser sublinhado é a questão avaliativa. Concordamos com RODRIGUES (1998), que afirma que a avaliação em educação a distância deverá ser apresentada em um modelo centrado na aprendizagem, que busca os elementos envolvidos no planejamento, na construção, na elaboração, na aplicação e na avaliação do processo de ensino-aprendizagem, correlacionando os itens e destacando sua interdependência.

Além disso, os processos devem ser claros e a confiança mútua. Não somente no momento avaliativo, mas no conjunto de ações a serem realizadas por alunos, alunos e professores ou em grupos de trabalho. Neste momento entramos no mérito da responsabilidade, esta que deverá partir do aluno em relação ao seu desenvolvimento, mas, ao mesmo tempo, ser apoiada por todos os atores da aprendizagem.

A avaliação deve ser vista como uma prática formativa, composta pelas múltiplas atividades desenvolvidas no decorrer do curso. Também devemos coibir o meramente treinar, atentando para que a educação a distância desenvolvida nas empresas priorize a aprendizagem.

Para GUTIERREZ e PRIETO (1994), a avaliação ideal em sistemas de ensino a distância seria a auto-avaliação, capaz de integrar processos e produtos, de corrigir e estimular a auto-aprendizagem e de construir, experimentar e simular novos conhecimentos.

"O tratamento pedagógico tem como função essencial facilitar a obtenção de produtos mais adequados aos diferentes momentos da auto-aprendizagem: apropriação de informação, recriação, semântica, aplicabilidade, relação texto-contexto, invenção etc.” (GUTIERREZ e PRIETO, 1994, P.131)

Desta forma, é de fundamental importância proporcionar aos alunos a possibilidade de um reestudo, pois é através deste que os mesmos poderão analisar em seu dia-a-dia o motivo de suas conclusões em relação as informações e procedimentos levantados ao longo de sua formação. Este é o ideal da educação, não tomar o erro como algo definitivo, mas como uma possibilidade. 


\section{Considerações Finais}

Quando falamos em educação a distância muitas empresas tendem a perceber a mesma como uma forma de treinamento massificante. Devemos deixar claro que este não é o objetivo da EAD. Ao contrário, esta modalidade de educação continuada visa proporcionar a um maior número de pessoas conhecimento, além de possibilitar um ensino adequado às peculiaridades do educando.

COSTA (2002), enfatiza que o foco na aprendizagem, o reforço da interação professor $\mathrm{x}$ aluno, a inclusão de estratégias de trabalho colaborativo e uma aprendizagem mediada por materiais que estimulem os alunos a processar a informação autonomamente e de modo significativo, são os eixos essenciais associados a uma mudança de paradigma pedagógico e que , nesse sentido, parecem enquadrar algumas das propostas mais consistentes de e-learning. A partir disto, acreditamos que embora a expressão em inglês signifique "aprendizagem eletrônica", representando, assim, a relação entre tecnologia e aprendizagem, o foco da educação é sempre o aprender. Sendo assim, é necessário refletir no sentido de que a implementação de projetos de educação a distância não será simples e deverá inicialmente estar voltada para a preparação de formadores, uma vez que, este desempenha um papel decisivo no processo de planejamento, avaliação e concepção, e deles também dependerá o sucesso de formas inovadoras de ensinar à distância.

Assim, os modelos atuais de EAD que primam pelo uso de tecnologias cada vez mais avançadas, recursos mais confiáveis, devem ser aliados a características pedagógicas de iniciativa, intervenção e mediação para que a prática a distância não acabe por tornar-se decontextualizada, meio como fim. Esta é principal preocupação que encontramos a respeito de educação a distância: a junção dos fazeres pedagógicos e técnicos.

Enfatizamos o conceito de comunicação em EAD, pois cremos que é através da participação do aprendente que a educação ocorre. Acreditamos que a partir de mudanças pontuais na comunicação - em exemplo a comunicação entre sujeitos cognoscentes e não mais polarizados - alavancaria a educação a distância para um nível de compreensão e aceitação, por parte da sociedade, muito maior. Solicitando aos aprendentes participação ativa e politizada, ao contrário do que hoje ocorre em muitas plataformas de ensino a distância.

Entretanto, a comunicação não é o único pilar da educação, também existem a interação, a colaboração, a cooperação, a reflexão. Sentenças com características distintas, mas que através da participação tornam-se híbridas em um processo de interdisciplinaridade. Desta forma, verificamos na EAD uma prática mais dialógica e humanista, pois vale-se de recursos diversos para tornar o educando comprometido e coerente na construção de seus conhecimentos.

Infelizmente, não são todas as formas de educação a distância que utilizam-se destes mecanismos, em diversos segmentos encontramos formas divergentes, como ensino bancário (repetição), o ensino massificante (não há individual, só o grupo) etc. Acreditamos que estas modalidades iram gradualmente ser extintas, só dependendo do senso crítico de discentes, docentes e dos agentes envolvidos nos projetos de educação a distância.

Um ponto que gostaríamos de salientar na educação a distância é o feedback; imediato ou individualizado, é de extrema importância para o aluno que encontra-se geograficamente disperso e sem contato com a presença física do professor. 
De acordo com CATAPAN \& FIALHO (1999), a provisoriedade do conhecimento exige cada vez mais investimentos, encontrando na educação a distância uma forte aliada para as empresas que visam capacitação constante de seu quadro de funcionários. Salientamos como alguns pontos favoráveis neste contexto: custo por treinando inferior a um curso tradicional, redução no custo com viagens e respectiva falta do funcionário na empresa, tempo de treinamento menor, pois é dado ao funcionário o curso adequado às suas reais necessidades, ou seja, módulos específicos e capacidade de auto-desenvolvimento do funcionário.

Enfim, cremos que a construção de uma aprendizagem significativa é o caminho a ser percorrido pela educação a distância, seja através da educação formal ou continuada. Para tanto, verificamos que os modelos vigentes de educação a distância deverão ser modificados às necessidades do educando, sejam elas de participação, interação, avaliação, mediação ou quaisquer outras para que a educação esteja correlacionada com seu real objetivo: o aprender.

Enfim, é através de uma prática coerente e reflexiva que a educação a distância, seja formal ou informalmente, remeterá o aprendente a competências como a criatividade e a autonomia, indispensáveis à realidade atual..

\section{Referências}

BELLONI, Maria Luiza. A Mediação Pedagógica: Educação a Distância Alternativa. 2. ed. Campinas. Autores Associados: 2001.

CATAPAN, Araci. FIALHO, Francisco Antonio. Autonomia e Sensibilidade na Rede: Uma Proposta Metodológica. Revista Brasileira de Educação a Distância. Ano 6. N 36. Setembro/outubro de 1999.

COGO, Denise. Tendências na Comunicação. V. 4. Porto Alegre: L \& PM, 2001.

COSTA, Fernado Albuquerque. PERALTA, Maria Helena. Formação de Formadores para a Construção de Contextos de Aprendizagem Significativa. 2002. Disponível em < www.fpce.ul.pt/pessoal/ulfpcost/ > acesso em 14 de abril de 2003.

GUTIERRES, Francisco e PIETRO, Daniel. A Mediação Pedagógica: Educação à Distância Alternativa. Editora Papirus. Campinas, 1994.

KNELLER, George. Arte e Ciência da Criatividade. São Paulo: Ibrasa, 1988. P94-106.

MARTINS, Francisco E. M. (et. Al.). Tendências na Comunicação. Porto Alegre: L \& PM, 1998.

MATURANA, Humberto. Emoções e Linguagem na Educação e na Política. Belo Horizonte: UFMG, 1998.

MORAN, José Manuel. Novas Tecnologias e o Reencantamento do Mundo. Tecnologia Educacional. V. 23. São Paulo, no 126, set/out 1995, p.24-26.

NEGROPONTE, Nicholas. A Vida Digital. São Paulo: Companhia das Letras, 1995.

RODRIGUES, Rosângela. Modelo de Avaliação para Cursos de Ensino a Distância estrutura, aplicação e avaliação. Tese de Mestrado em Engenharia de Produção. Área de Mídia e Conhecimento. UFSC: Florianópolis, 1998. 